\title{
Hydrologic and Isotopic Modeling of Alpine Lake Waiau, Mauna Kea, Hawai ${ }^{i}{ }^{1}$
}

\author{
Bethany L. Ehlmann, ${ }^{2}$ Raymond E. Arvidson, ${ }^{2}$ Bradley L. Folliff, ${ }^{2}$ Sarah S. Fobnson, ${ }^{3}$ Brian Ebel, ${ }^{4}$ \\ Nicole Lovenduski, ${ }^{5}$ Julie D. Morris, ${ }^{2}$ Jeffery A. Byers, ${ }^{6}$ Nathan O. Snider, ${ }^{2}$ and Robert E. Criss ${ }^{2}$
}

\begin{abstract}
Analysis of hydrologic, meteorologic, and isotopic data collected over $3 \mathrm{yr}$ quantifies and explains the enormous variability and isotopic enrichment $\left(\delta^{18} \mathrm{O}=+16.9, \delta \mathrm{D}=+50.0\right)$ of alpine Lake Waiau, a culturally and ecologically significant perched lake near the summit of Mauna Kea, Hawai'i. Further, a simple one-dimensional hydrologic model was developed that couples standard water budget modeling with modeling of $\delta \mathrm{D}$ and $\delta^{18} \mathrm{O}$ isotopic composition to provide daily predictions of lake volume and chemistry. Data analysis and modeling show that winter storms are the primary source of water for the lake, adding a distinctively light isotopic signature appropriate for high-altitude precipitation. Evaporation at the windy, dry summit is the primary loss mechanism for most of the year, greatly enriching the lake in heavy isotopes.
\end{abstract}

Lake Waiau is located within the $\mathrm{Pu}^{\prime} \mathrm{u}$ Waiau cinder cone on Mauna Kea Volcano at an elevation of $3,960 \mathrm{~m}$ above mean sea level and is the third highest lake in the United States (Gregory and Wentworth 1937, Woodcock et al. 1966, Woodcock and Groves 1969, Woodcock 1980) (Plate I). The small lake (average surface area, $\sim 0.6 \mathrm{ha}$ ) is the only open body of water sustained yearround on the cold, arid summit. Annual precipitation, which ranges from $\sim 12$ to $45 \mathrm{~cm}$,

${ }^{1}$ The Olin Foundation and Washington University provided support for this study. Manuscript accepted 20 February 2004.

${ }^{2}$ Department of Earth and Planetary Sciences, Washington University, St. Louis, Missouri 63130.

${ }^{3}$ Department of Earth, Atmospheric, and Planetary Sciences, Massachusetts Institute of Technology, Cambridge, Massachusetts 02139.

${ }^{4}$ Department of Geological and Environmental Sciences, Stanford University, Palo Alto, California 94305.

${ }^{5}$ Department of Atmospheric Sciences, University of California, Los Angeles, California 90095.

${ }^{6}$ Division of Chemistry and Chemical Engineering, California Institute of Technology, Pasadena, California 91125 .

Pacific Science (2005), vol. 59, no. 1:1-15

(C) 2005 by University of Hawai'i Press

All rights reserved falls mostly during a few large winter storms (Massey 1978, Schroeder 1993).

The presence of the lake at the summit presents a challenge in terms of understanding the hydrology of the overall summit system. The lake is also of interest because it supports an ensemble of unique microorganisms (Massey 1978, Kinzie et al. 1998) and is a culturally important part of the summit region. Numerous archaeological sites surround the lake region, and offerings still made by native Hawaiians testify to the continuing deep cultural symbolism associated with the cone, the lake, and the sacred summit or wao akua (region of the gods) (Group 70 International, Inc. 2000). The summit region in general and Lake Waiau in particular have recently become a focal point for scientific and cultural concern because of proposed new construction at the Mauna Kea Observatory Complex (e.g., Group 70 International, Inc. 2000, Reichhardt 2002).

Scientific reports and data on Lake Waiau are few. Research on Mauna Kea hydrogeology establishes that the near-summit hydrologic system is dominated by ephemeral stream flow in response to storm-induced precipitation and rapid snowmelt (Stearns and Macdonald 1946, Woodcock and Groves 1969). Electrical resistivity studies show that the main water table on Mauna Kea is many 
thousands of meters below the summit of the mountain (Zohdy and Jackson 1969). Shallow subsurface flow is guided downhill by the presence of impermeable substrates (Woodcock 1980). Some of this water reappears at numerous small seeps and springs on the upper flanks of the volcano.

The Pu'u Waiau cinder cone in which Lake Waiau is located is breached on the northern side by a basalt flow that drapes down into the cone (Plate II). The lake is thought to exist due to a combination of the presence of a closed basin defined by the cone interior and the basalt flow and a relatively impermeable substrate that inhibits groundwater loss (Gregory and Wentworth 1937, Woodcock and Groves 1969). Woodcock et al. (1966) found lake-bottom sediments extending more than $7.5 \mathrm{~m}$ deep. Both hydrothermally altered, fine-grained ash and permafrost have been proposed as the cause of the low permeability (Ugolini 1974, Woodcock 1980). At the contact of the northwestern rim of the cinder cone and flow, there is a topographically low $\mathrm{V}$-shaped notch underlain by jointed flow outcrop. During lake highstands, Lake Waiau has been observed to overflow into Pōhakuloa Gulch through this depression (Plates I and II). Woodcock (1980) observed spillover rates of up to 164 $\mathrm{m}^{3} /$ day.

Because of the scientific and cultural interest in Lake Waiau, we undertook a detailed study of the lake to better quantify and understand its hydrology. This work consisted of mapping of topographic profiles within the lake drainage basin and collection of water samples for isotopic analysis, followed by detailed analysis of the data and construction of a water balance model to quantify the hydrologic cycle.

\section{MATERIALS AND METHODS}

The study was undertaken in two parts. Part one consisted of data collection on the summit of Mauna Kea: drainage basin mapping, water sample collection for stable isotope analysis, lake level measurements, and an evaporation pan experiment. Data collection was followed by analyses to infer key hydrologic processes associated with the lake. Part two was the construction of a simple, first principles computer-based hydrologic model that daily calculates lake depth and stable isotope ratios, ${ }^{2} \mathrm{H} /{ }^{1} \mathrm{H}$ and ${ }^{18} \mathrm{O} /{ }^{16} \mathrm{O}$.

\section{Basin Surveying and Lake Bathymetry}

The first step in our analysis was to map the drainage basin associated with the lake and determine the geometry of the spillover channel. Mapping done by us in August 2001 included acquisition of ground topographic profile surveys taken radially and tangentially to the lake shoreline as well as transects along and perpendicular to the long axis of the spillover channel. A USGS-provided digital elevation map (DEM) for the summit with pixels $10 \mathrm{~m}$ wide (U.S. Geological Survey 1982) was then acquired and cross-compared with the field-based surveys to verify the accuracy of the elevation data for use in hydrologic modeling. Comparison of the ground surveys and USGS elevation data showed that the USGS data were accurate to better than a few meters in the vicinity of $\mathrm{Pu}^{\prime} \mathrm{u}$ Waiau. To generate a three-dimensional model of the basin including the lake bottom, the lake depth contour map of Woodcock (1980) was digitized to model lake bathymetry. These data were then combined with the USGS elevation map to generate a full basin digital elevation model for the lake and its drainage system.

The next step was to utilize the Watershed Monitoring System software Topographic Parameterization Program (TOPAZ) (see Garbrecht and Martz 1995, 1997) to produce maps of fine-scale flow pattern and drainage basins. The area of the Lake Waiau drainage basin was computed on the basis of the drainage maps and drainage basin divides produced by the Watershed Monitoring System.

Finally, lake surface area as a function of depth was acquired by least squares fitting a log-log linear function to depth and surface areas provided in the Woodcock (1980) bathymetric contour map. Lake volume as a function of depth was derived using a numerical integral approximation of the volume 
using surface area with a depth integration step of $1 \mathrm{~cm}$.

\section{Isotopic Sampling and Evaporation Pan Experiment}

Isotope hydrology is a well-established discipline for understanding sources of water and hydrologic processes (Criss 1999). To ensure a robust data set for understanding the hydrology of Mauna Kea, generally, and Lake Waiau, specifically, we collected precipitation at three elevations on Mauna Kea, spring waters from five springs on the flanks of the mountain, and waters from Lake Waiau (along with lake level) in August of 1999, 2000, and 2001 and in February 2002 (see Table 1). Samples for isotopic analysis were collected in bottles with polyseal caps. Oxygen isotope measurements were made using the standard carbon dioxide equilibration technique using a mass spectrometer (Finigan MAT 252). Hydrogen isotope concentration measurements were made using the zinc reduction technique (Coleman et al. 1982).

To gauge the summit evaporation rate, a 4-day evaporation pan experiment was also conducted from 18 August to 22 August 1999. Because a standard Class A pan was not available for installation at the site of the lake, two 24 by $30 \mathrm{~cm}$ aluminum pans were used. Water from the lake was placed in the pan and samples were collected every $24 \mathrm{hr}$ during the course of the pan experiments.

\section{Hydrologic Modeling}

To understand the collected data and to further characterize lake hydrologic dynamics over longer time periods when direct sampling at Lake Waiau could not be performed, a first principles hydrologic model was constructed in which water inputs and outputs by volume and isotopic composition were calculated using daily meteorological data acquired from the nearby Very Large Baseline Array (VLBA) Observatory (Plate I). Depth and isotope measurements from August 1999 were used as initial conditions.

weather data. The VLBA weather station is located southeast of the lake at an ele- vation of $3,720 \mathrm{~m}$. Data from this weather station, although not precisely representative of conditions at Lake Waiau, provide a record of summit meteorological conditions at near lake elevation. The weather station consists of a wind vane, anemometer (Qualimetrics Model 2020), and hygrothermometer (TSL Model 1063) located on a 10-m tower. At the base of the station are a barometer (Air Instruments Research DB-2AX) and rain gauge (Qualimetrics 6021-B). Our model utilized the station records of temperature, pressure, dew point, and wind speed taken every 8.5 min. After discarding data values tagged as unreliable, 8.5 -min data were averaged to provide daily values. The daily precipitation value used was the last rain gauge level recorded by the weather station for a particular day.

VOLUMETRIC MODELING. Inputs to the lake were direct precipitation onto the lake $(P)$ and runoff from its small basin $\left(Q_{\text {runoff }}\right)$ (Figure 1). Outputs were evaporation $(E)$, spillover $\left(Q_{\text {spillover }}\right)$, and seepage through a cracked basalt layer $\left(Q_{\text {sepage }}\right)$ identified by us during fieldwork. The water balance equation for the lake was

$$
\frac{d V}{d t}=P+Q_{\text {runoff }}-E-Q_{\text {spillover }}-Q_{\text {seepage }}
$$

The model timestep $d t$ was 1 day and all values were calculated in $\mathrm{m}^{3} /$ day. Based on previous studies (Ugolini 1974, Woodcock 1980), we assume that the lake is perched on impermeable substrate. Thus, flux into or out of the bottom of the lake was assumed to be negligible (though the model accounts for subsurface input derived from precipitation falling interior to the basin-see discussion of the $Q_{\text {runoff }}$ parameter in the next paragraph). Using the results of basin modeling, surface area and depth of the lake were computed from lake volume.

Direct precipitation input for a given day $(P)$ was calculated simply by multiplying the modeled lake area by the recorded amount of precipitation for the day. $Q_{\text {rumoff }}$ was calculated using a linear reservoir model to introduce a time lag (Bras 1990). For each day with precipitation, a new $Q_{i}(t)$ function to model 


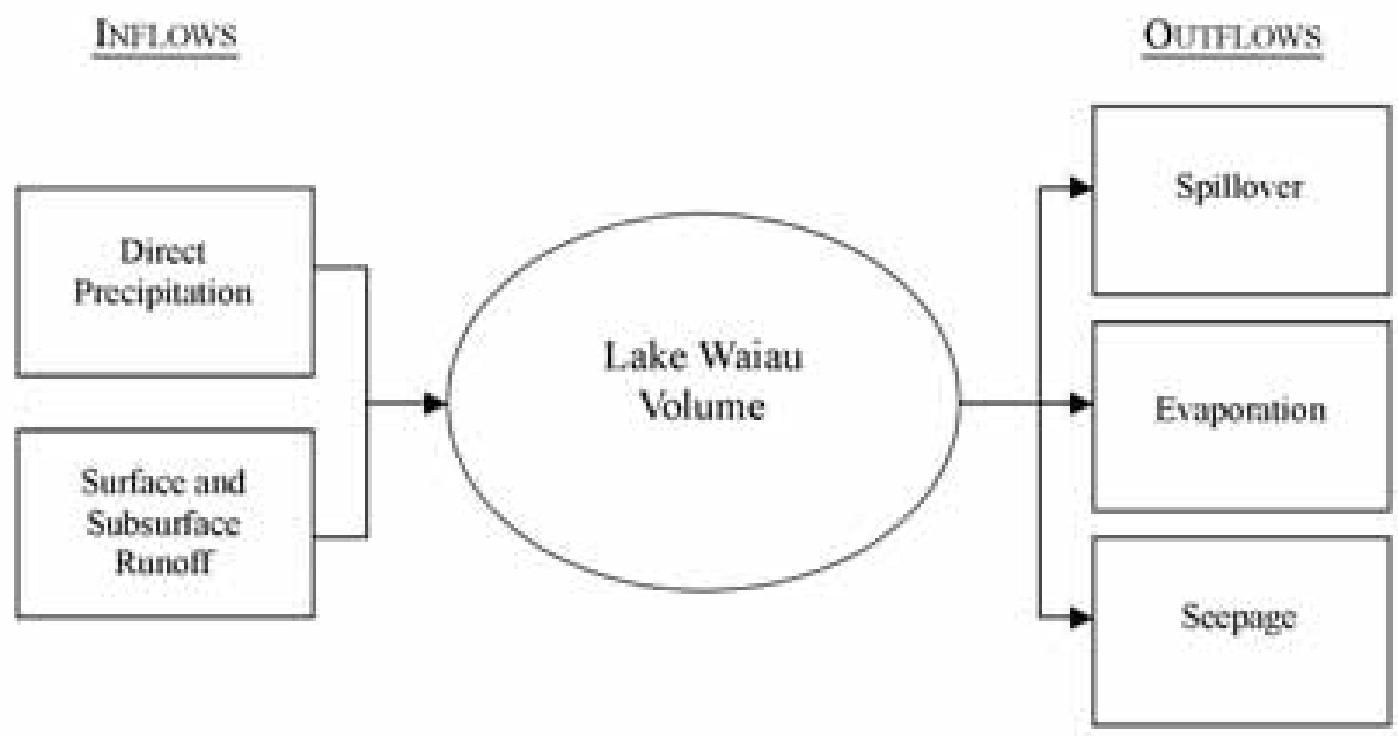

FIgURE 1. Schematic of the modeled inflows and outflows of Lake Waiau.

runoff was created according to the equation

$$
\begin{aligned}
Q_{\text {runoff }} & =Q_{i}(t) \\
& = \begin{cases}I_{i} q_{f}\left(1-e^{-t / k}\right) & \text { for } t<i \\
I_{i} q_{f}\left(e^{-(t-i) / k}-e^{-t / k}\right) & \text { for } t \geq i\end{cases}
\end{aligned}
$$

where on model day $i, I_{i}$ is the runoff generated from that day's precipitation [(basin area - lake surface area) $\times$ precipitation]. $q_{f}$ is the percentage of runoff actually making it into the lake; the remainder is lost to evaporation or remains trapped in pore spaces of the rocks. $t$ is the model time and $k$ is the mean time for runoff input, which includes factors such as melt time if the precipitation were sleet or snow. ( $q_{f}$ and $k$ cannot be measured directly and were estimated during model runs.) For each model day $i$, the values of all $Q_{i}(i)$ were summed to provide the modeled input from runoff.

In calculating water balance model outputs, the Penman method was used to model evaporation $(E)$ from the surface of the lake (Ponce 1989, Singh 1992). Meteorological data needed for the calculations-air temperature, pressure, wind speed, and relative humidity (determined from recorded dew point) - were provided by VLBA Observa- tory weather data. Lake surface area was provided from daily volumetric modeling, and water surface temperature was estimated using mean monthly lake temperature data collected from 1965 to 1967 (Woodcock 1980).

At high lake levels, i.e. when lake depth exceeded $2.3 \mathrm{~m}$ waters, were lost by spillover into a low area on the west side of the lake (Woodcock 1980). An empirical dischargeto-height relationship was created by approximating the Lake Waiau spillway opening as a weir. The weir geometry was determined using a cross section from our ground survey transects. The slope of the roughly triangular opening was found to be 8.5 degrees. A weir equation to calculate spillover volume as a function of depth was calculated using equation 7-94 from Chow (1964) and calibrated based discharges measured during 1965 to 1976 (Woodcock 1980). Specifically, the maximum discharge observed by Woodcock (1980), $\sim 164 \mathrm{~m}^{3} /$ day, occurred when the lake was approximately $8 \mathrm{~cm}$ above the spillover depth. The triangular weir equation resulting from this calibration is

$$
Q(b)_{\text {spillover }}= \begin{cases}4645.5 \times b^{2.5} & \text { for } b \geq 2.3 \mathrm{~m} \\ 0 & \text { otherwise }\end{cases}
$$



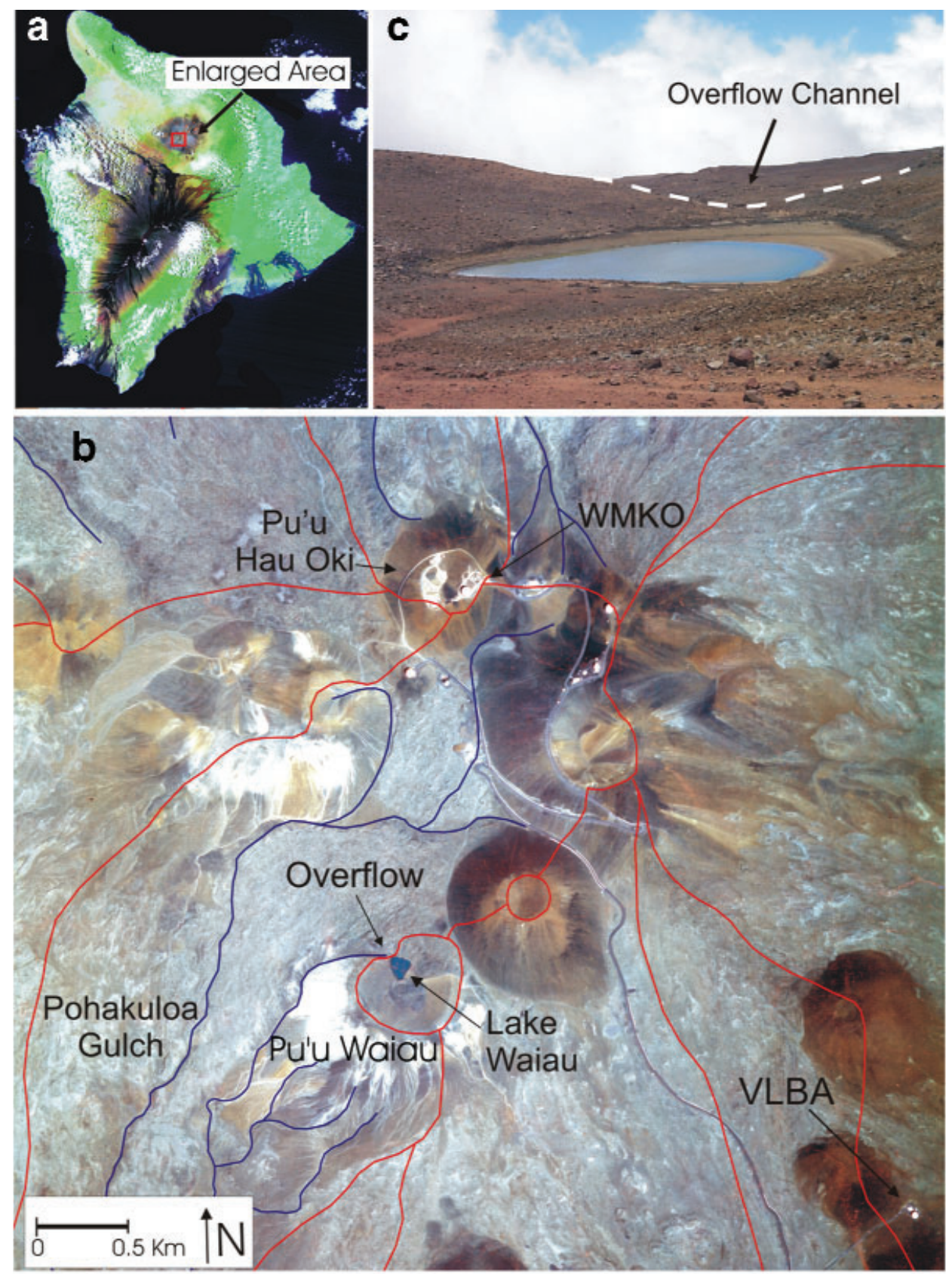

Plate I. Lake Waiau and Mauna Kea summit map. $a$, Landsat image of the Big Island of Hawai' $i$, showing study area. $b$, False-color infrared aerial photograph acquired in December 1992 showing summit area of Mauna Kea and Lake Waiau, overlain with drainage divides (red lines) and major drainage channels (blue lines) derived from analysis of the basin topography (detailed in text); WMKO, William Keck Observatory; VLBA, Very Long Baseline Array (acquisition date: 30 September 1992, frame 107, Eros Data Center ID AB592004485). c, Ground view of Lake Waiau at 0.6 ha acquired in August 2000, with spillover lip outlined. 

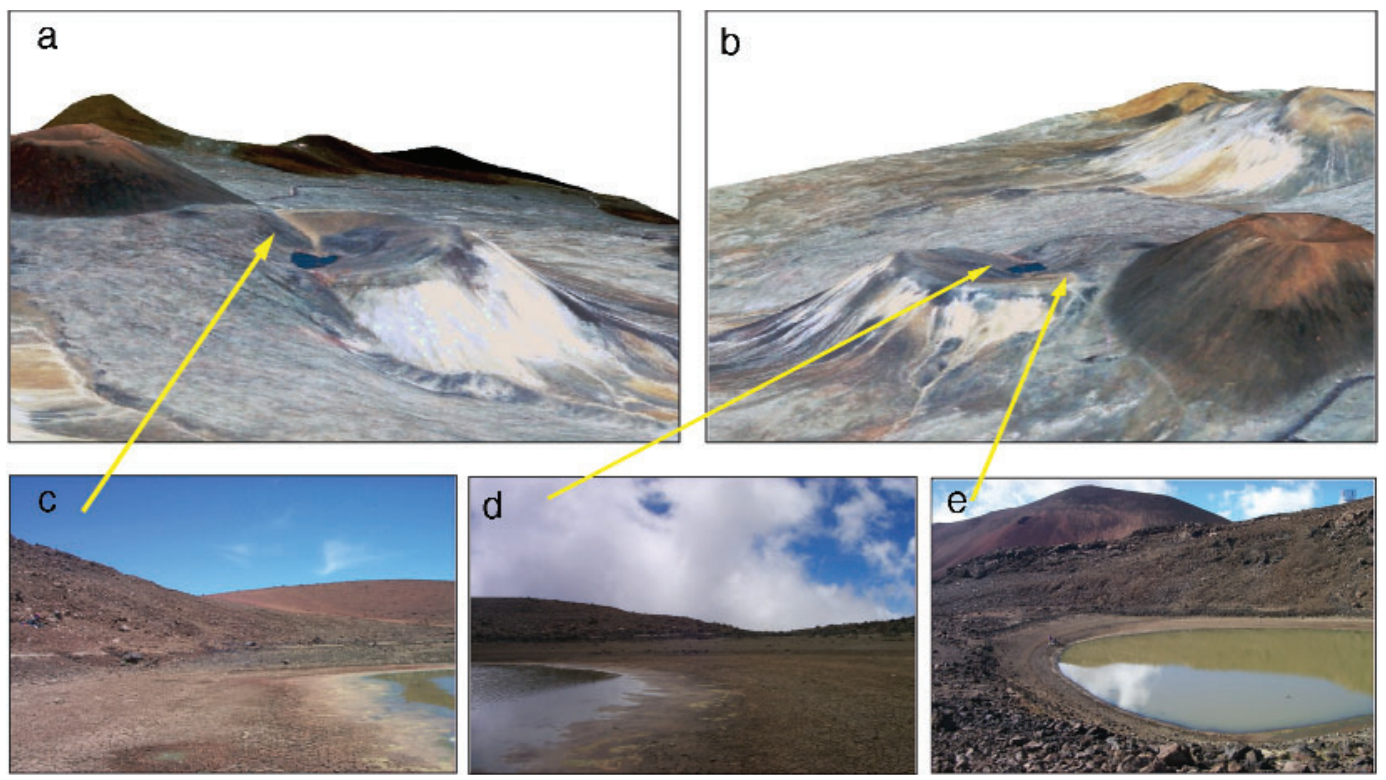

PLATE II. The false-color infrared photograph of Plate I overlain on a U.S. Geological Survey digital elevation model (DEM) (1982) of the summit. $a$, View of the Pu'u Waiau cone looking southeast. A basaltic lava flow drapes over the cinder cone on the north side. $b$, View of $\mathrm{Pu}^{6} u$ Waiau looking west over the mouth of the spillover channel. Lower images are photographs taken in August 1999 when the lake depth was quite low $(0.5 \mathrm{~m}): c$, a white bench marks the lake's highstand at $2.3 \mathrm{~m}$ in depth; $d$, a roughly triangular notch in the cone allows lake waters to spill over to the northwest; $e$, view from the southeast looking at the lava flow that forms the northern boundary of the lake basin. 
In addition, loss was allowed by seepage when lake level was above the base of a fractured basalt layer that rings the lake on the western side and extends about $1 \mathrm{~m}$ below the lake's maximum depth (Plate II). When lake depth exceeded $1.3 \mathrm{~m}$, seepage was modeled as $Q_{\text {sepage }}=C A_{x}$, where $A_{x}$ is the cross-sectional area through which seepage occurs and is estimated from the lake circumference and the level of the water above the basalt layer. $C$ is a constant, estimated by the optimization program (see discussion of model calibration in Results), during model runs that accounts for hydraulic conductivity and hydraulic head (change in head due to lake depth variation $[<1-2 \mathrm{~m}]$ was assumed to be negligible).

ISOTOPIC MODELING. Modeling of daily lake depth $(\delta \mathrm{D})$ and stable isotopic $\left(\delta^{18} \mathrm{O}\right)$ compositions was undertaken to provide additional constraints on the lake's hydrologic dynamics. A three-step approach was taken to modeling isotopes. First, precipitation and watershed runoff were treated as a linear mixing event: new lake isotopic composition was calculated by computing a weighted average of the isotopic composition of the old lake and the added precipitation according to

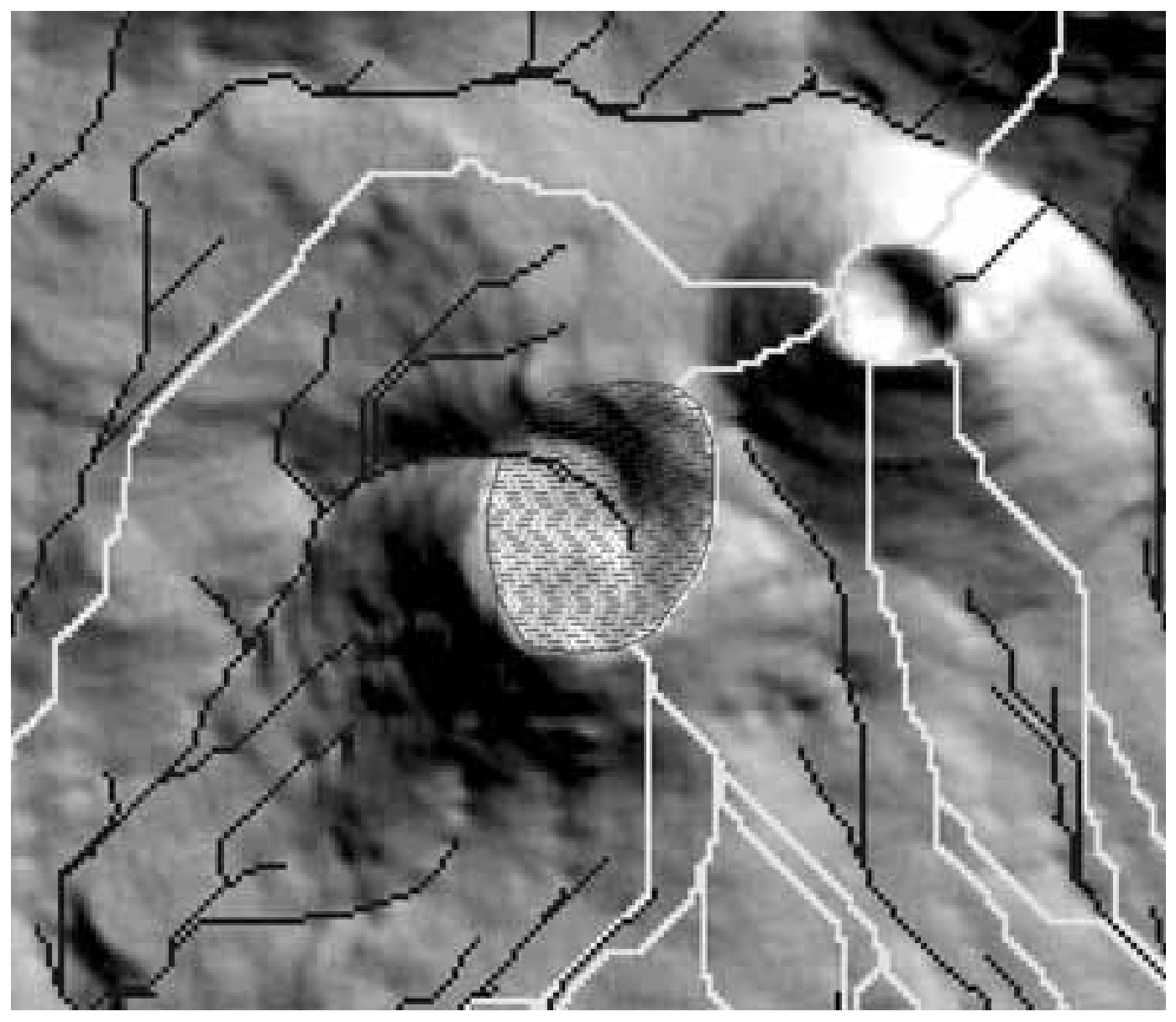

Figure 2. Drainage map of the Mauna Kea summit created with the TOPAZ-Watershed Monitoring System package and overlain on a shaded relief map of the summit created from the USGS Digital Elevation Model. Image width is $2 \mathrm{~km}$. The white lines are drainage basin divides and the black lines represent drainage networks. The dashed oval marks the estimated drainage basin area for Lake Waiau. 


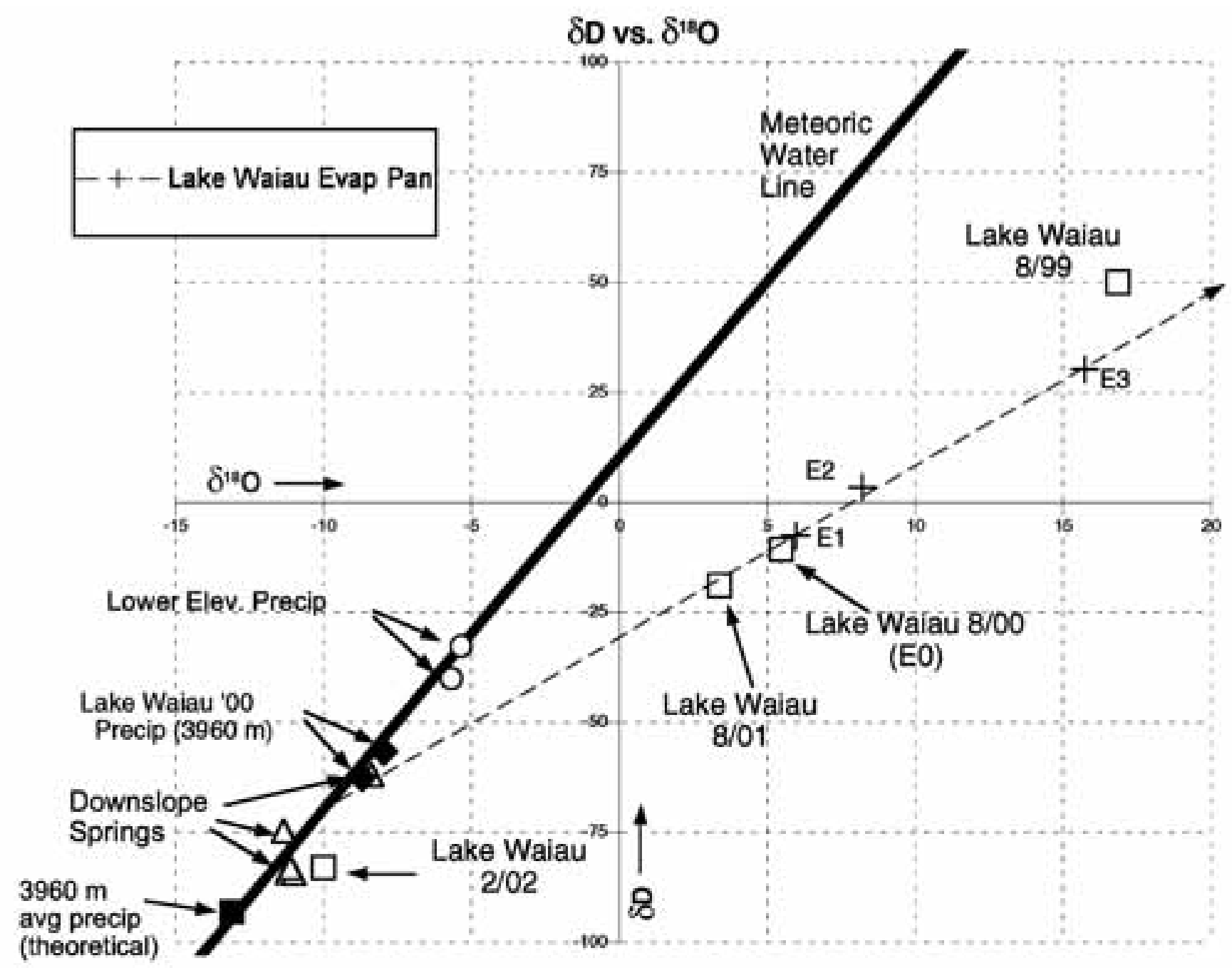


the mass balance equation

$$
\delta_{\text {mix }}=f_{\text {precip }} \times \delta_{\text {precip }}+\left(1-f_{\text {precip }}\right) \times \delta_{\text {lw }} .
$$

The parameters $\delta_{\text {precip }}, \delta_{\mathrm{lw}}$, and $\delta_{\text {mix }}$ refer to the isotopic compositions of precipitation, lake water before mixing, and lake water after mixing, respectively; and $f_{\text {precip }}$ is the fraction of "new" lake water from precipitation (direct + runoff). Isotope fractionation in runoff waters was assumed to be insignificant. The value of $\delta_{\text {precip }}$ varied seasonally: from May to September, $\delta_{\text {precip }}$ value used was that of collected summer precipitation. The rest of the year, the value used was a theoretical value calculated using the technique of Scholl et al. (1996) (see Results for discussion of precipitation seasonality).

Second, water was lost by spillover or seepage, which resulted in a lake volume change but no change in isotopic composition. Third, isotopic change in lake waters induced by evaporation was modeled, also by linear mixing

$$
\delta_{l w}=\frac{\delta_{m i x}-f_{\text {evap }} \times \delta_{E}}{\left(1-f_{\text {evap }}\right)}
$$

where $f_{\text {evap }}$ is the fraction of the lake water lost during evaporation and $\delta_{l w}$ is the new isotopic composition of the lake after all the day's inputs and outputs. The theoretical isotopic composition of the water evaporated, $\delta_{E}$, is computed from the relation

$$
\frac{\delta_{W}-\delta_{w}^{s}}{\delta_{E}-\delta_{w}^{s}}=\alpha_{\text {evap }}^{0}(1-b)
$$

obtained from equations 4.30 and 4.35 of Criss (1999). In this new relation, $\delta_{W}$ equals $\delta_{m i x}$ already described. $b$ is relative humidity. $\delta_{W}^{s}$ is the "stationary" state isotopic composition for water after evaporation has gone on for a long time and is obtained by

$$
\delta_{w}^{s}=\frac{\alpha_{e q} h\left(1,000+\delta_{v}\right)}{1-\alpha_{\text {evap }}^{0}(1-b)}-1,000
$$

where $\delta_{v}$, the isotopic composition of vapor in the atmosphere, is estimated from $R_{v}=$ $R_{\text {precip }} / \alpha_{e q} . \alpha_{e q}$ is the fractionation factor between water and water vapor $\left[\alpha_{e q}=(1,000+\right.$ $\left.\left.\delta_{\text {precip }}\right) /\left(1,000+\delta_{v}\right)\right]$ at equilibrium $(b=1)$ and varies according to temperature (Table 3.2 in Criss [1999]). $\alpha_{\text {evap }}^{0}$ is the nonequilibrium fractionation factor between water and water vapor at any instant under zero humidity $(b=0)$ and can be approximated from $\alpha_{e q}$ using Table 4.2, equations 4.66 and 4.67 of Criss [1999]).

\section{RESULTS}

Our drainage basin mapping shows that Lake Waiau is fed by a small, 135,000- $\mathrm{m}^{2}$ circular basin that includes the inner walls of $\mathrm{Pu}^{6} \mathrm{u}$ Waiau and a portion of the basalt lava flow on the northern side of the lake (Figure 2). This basin is isolated from the surface drainage of the current and planned telescope sites and their drainage systems. In addition, results of our mapping corroborate previous data (Woodcock 1980) that show that when Lake Waiau depth exceeds $2.3 \mathrm{~m}$, spillover occurs through Pohakuloa Gulch to the northwest. On-site measurements of lake depth show that lake levels were low in August 19992001 (0.5, 0.8, and $1.04 \mathrm{~m}$, respectively) compared with February 2002 when lake level was at $2.35 \mathrm{~m}$ and overflowing.

The next step of our analyses was to examine isotopic compositions of the collected rainwater, springs, and lake water. The $\delta \mathrm{D}$ and $\delta^{18} \mathrm{O}$ values of precipitation decrease as a function of elevation, a trend consistent with preferential precipitation of heavy isotopes of water as air ascends the flanks of Mauna Kea (Figure 3). (Note that, for example, $\delta \mathrm{D}=$ $1,000\left[(\mathrm{D} / \mathrm{H})_{\text {sample }} /(\mathrm{D} / \mathrm{H})_{\text {SMOW }}-1\right]$, where SMOW is standard mean ocean water and $\mathrm{D} / \mathrm{H}$ is the deuterium to hydrogen ratio). This fractionation pattern follows the well-

FIgURE 3. $\delta \mathrm{D}$ versus $\delta^{18} \mathrm{O}$ stable isotope measurements of Mauna Kea waters. Meteoric Water Line (MWL) is shown (Craig 1961). Precipitation collected at various altitudes, water collected from high-altitude springs (derived from rainwater), and the average precipitation isotopic composition predicted from Scholl et al. (1996) lie on the MWL, with heavy isotopes becoming progressively depleted with altitude. Lake Waiau samples plot on a slope less steep than the MWL. Daily samples from the 4-day August 2000 evaporation pan experiments with Lake Waiau water are denoted by E, and a best-fit trendline intersects the MWL near the isotopic composition of collected Lake Waiau summer precipitation. 

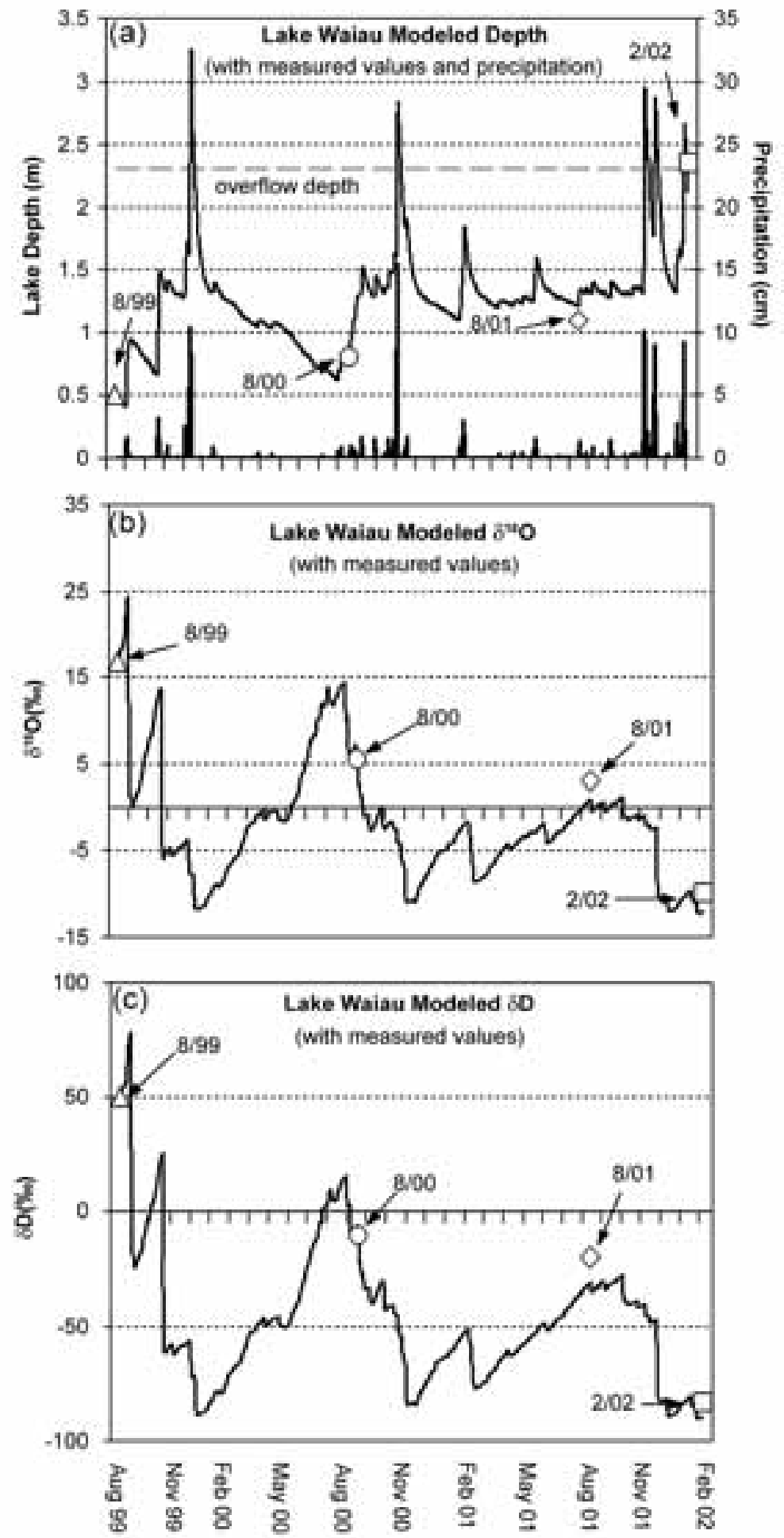
defined Meteoric Water Line (Craig 1961). Spring water is isotopically indistinguishable from high-altitude precipitation values and demonstrates that the source of spring water on the flanks of Mauna Kea is simply precipitation that falls at higher altitudes.

Scholl et al. (1996) quantified the seasonal isotopic variation in precipitation at high altitudes in Hawai'i. The volume-weighted mean precipitation at the elevation of the lake, corrected for seasonal variation using the equations of Scholl et al. (1996), was found to be quite light isotopically $(\delta \mathrm{D}=$ $\left.-93.2 \%, \delta^{18} \mathrm{O}=-13.1 \%\right)$. This is consistent with the bulk of annual precipitation (and thus lake input) coming from winter storms, which produce isotopically light precipitation (Scholl et al. 1996). Summer precipitation collected from vesicles of rocks near the lake in August 2000 is slightly heavier (average of collected precipitation: $\delta \mathrm{D}=-59.6 \%$, $\delta^{18} \mathrm{O}=-8.3 \%$ ). Spring waters collected downslope from the lake are also quite depleted in heavy isotopes (average: $\delta \mathrm{D}=$ $-77.6 \%, \delta^{18} \mathrm{O}=-10.6 \%$ ) and are even lighter isotopically than what is predicted for precipitation at the altitude of spring water collection. This is consistent with the source for spring waters being mostly from isotopically light winter precipitation that fell higher on the mountain.

Isotopic compositions of Lake Waiau water samples are shown in Table 1 and Figure 3. Lake water samples taken on the same day but at different depths and locations have isotopic signatures identical within measurement errors, indicating that the lake is well mixed, presumably by wind action. The $\delta \mathrm{D}$ and $\delta^{18} \mathrm{O}$ values show enormous variability over the study period. Lake water collected in the summer is quite heavy isotopically, whereas water collected in February 2002 is light, with $\delta \mathrm{D}$ and $\delta^{18} \mathrm{O}$ values close to the estimated mean summit precipitation value. Isotopic compositions of lake water plot along
TABLE 1

Selected Mauna Kea $\delta \mathrm{D}$ and $\delta^{18} \mathrm{O}$ Stable Isotope Measurements

\begin{tabular}{|c|c|c|}
\hline Sample & $\delta \mathrm{D}(\%)$ & $\delta^{18} \mathrm{O}(\%)$ \\
\hline Lake Waiau (14 August 1999) & 50.0 & 16.9 \\
\hline Lake Waiau (18 August 2000) & -10.7 & 5.5 \\
\hline Lake Waiau (14 August 2001) & -19.0 & 3.4 \\
\hline Lake Waiau (6 February 2002) & -83.1 & -10.0 \\
\hline Hopukani Springs $(3,182 \mathrm{~m})$ & -84.2 & -11.2 \\
\hline Waihū Springs (2,998 m) & -74.7 & -11.3 \\
\hline Liloe Springs $(2,719 \mathrm{~m})$ & -84.3 & -11.0 \\
\hline $\begin{array}{l}\text { Spring on western flank of } \\
\text { Pōhakuloa Gulch }(2,633 \mathrm{~m})\end{array}$ & -83.0 & -11.1 \\
\hline $\begin{array}{l}\text { Spring on western wall } \\
\text { of Waikahalulu Gulch } \\
(3,268 \mathrm{~m})\end{array}$ & -62.0 & -8.4 \\
\hline $\begin{array}{l}\text { Saddle Road precipitation } \\
\quad(1,890 \mathrm{~m})\end{array}$ & -32.6 & -5.3 \\
\hline $\begin{array}{l}\text { Visitor Center precipitation } \\
\quad(2,804 \mathrm{~m})\end{array}$ & -40.0 & -5.7 \\
\hline $\begin{array}{l}\text { Lake Waiau summer } \\
\text { precipitation, from vesicles (1) } \\
(3,960 \mathrm{~m} \text {, August 2000) }\end{array}$ & -62.7 & -8.7 \\
\hline $\begin{array}{l}\text { Lake Waiau summer } \\
\text { precipitation, from vesicles (2) } \\
(3,960 \mathrm{~m} \text {, August } 2000)\end{array}$ & -56.5 & -7.9 \\
\hline $\begin{array}{l}\text { High-elevation precipitation } \\
(3,960 \mathrm{~m} \text { [from Scholl et al. } \\
1996])\end{array}$ & -93.2 & -13.1 \\
\hline
\end{tabular}

a line with a slope less steep than the Meteoric Water Line. Lake values extrapolate back to the Meteoric Water Line average precipitation value, suggesting that lake water derives from precipitation and becomes isotopically heavy as a result of evaporation.

Results from the 4-day evaporation experiment corroborate this explanation for increasing $\delta \mathrm{D}$ and $\delta^{18} \mathrm{O}$ values. Lake water left in a pan by the shore became progressively enriched in heavy isotopes along a slope similar to that of measured lake isotopic variation. Evaporation rate during the pan experiment was high, $4.9 \mathrm{~mm} /$ day, which is

FIGURE 4. Modeled hydrology of Lake Waiau. Measured values are indicated by arrows. $a$, Large winter precipitation events cause rapid filling of the lake. Spillover and seepage cause water loss immediately after these events, and evaporation dominates the rest of the year. $b$ and $c$, Heavy isotopes in the lake become depleted after precipitation events and enriched as evaporation proceeds. 


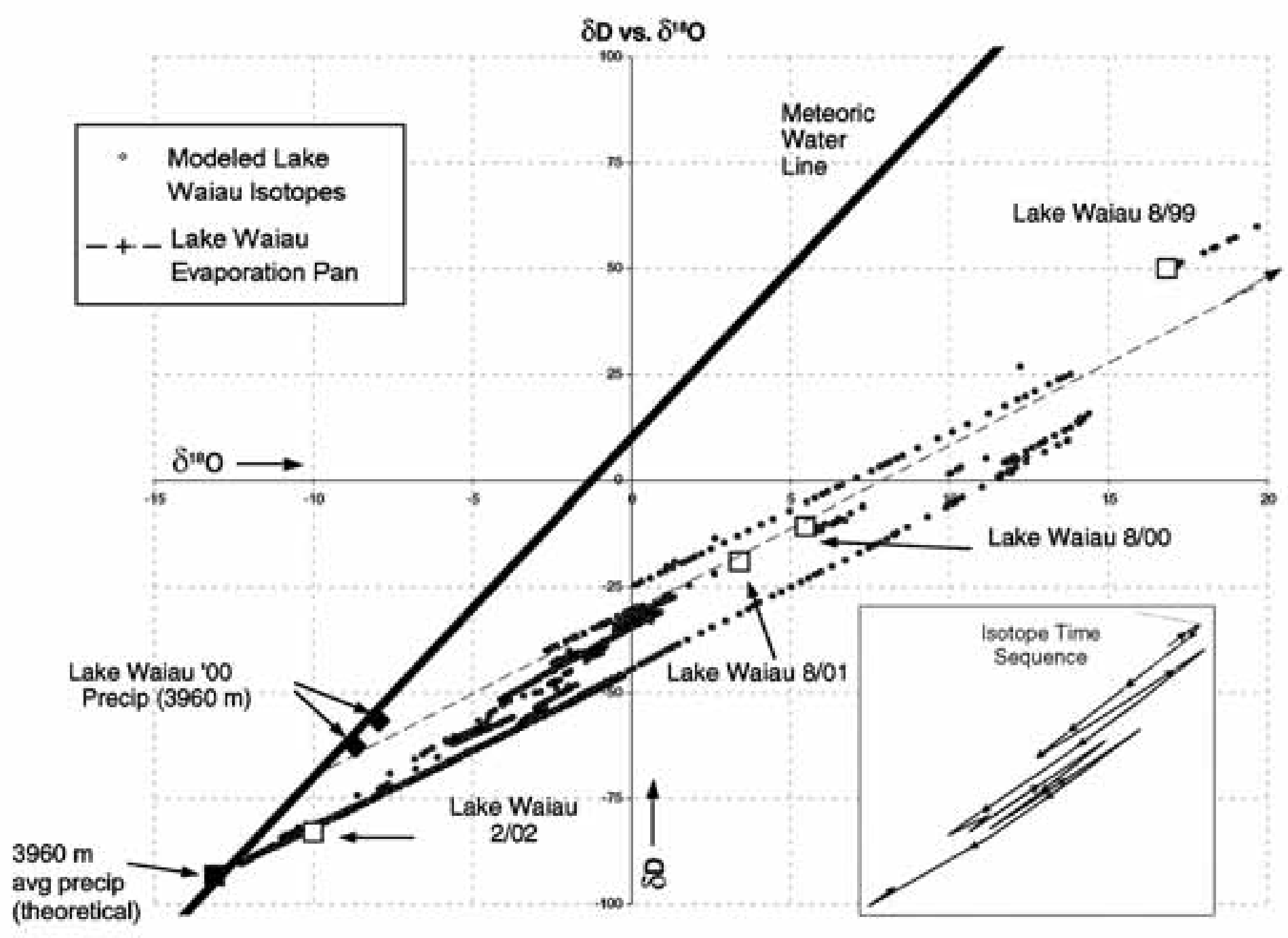


consistent with the value of $6.1 \pm 2.5 \mathrm{~mm} /$ day observed by Bean et al. (1994) at an elevation of 3,400 $\mathrm{m}$ on Mauna Loa.

Analyses of data thus suggest that in the winter, lake $\delta \mathrm{D}$ and $\delta^{18} \mathrm{O}$ values were extremely close to those of winter precipitation and the lake level was at overflow volume. In the summer, lake waters were significantly enriched in heavy isotopes along a slope similar to that of the evaporation pan. To test the hypothesis that the lake was fed only by precipitation in its basin, we used part two of our study, construction of the coupled onedimensional hydrologic model that calculates daily both $\delta \mathrm{D}$ and $\delta^{18} \mathrm{O}$ compositions based on input meteorological data.

The model was run on a daily basis from 15 August 1999 to 6 February 2002 and calibrated using data obtained on 19 August 2000, 14 August 2001, and 6 February 2002. In equations modeling the inputs and outputs of the lake, three parameters, the constant $C$ governing seepage through the basalt layer, mean time for runoff water to enter the lake $(k)$, and the percentage of water falling into the basin that actually enters the lake $\left(q_{f}\right)$, were constrained, but exact values were not known with certainty. The model was run several times with the three parameters varying within set constraints. After each model run consisting of 906 daily cycles, the percentage error was computed between modeled values and actual lake level and isotope data. An iterative, nonlinear optimization program (Box 1965) was employed to converge on the solution to the depth and isotopic temporal history from August 1999 to February 2002 that most closely matched actual measured values. Model error, a function of the three parameters, was minimized using the Complex method (Box 1965). The parameters were allowed to vary within $0<$ $C<5.0 \mathrm{~m} /$ day, $1.0<k<20$ days, $10 \%<$ $q_{f}<100 \%$. Random perturbations were incorporated into the method to avoid falling into local minima.
The model ran calculations on a daily basis and was calibrated using data obtained from August 1999 to February 2002. The values obtained for $C, k$, and $q_{f}$ that best model observed values were $2.25 \mathrm{~m} /$ day, 1.01 days, and $47 \%$, respectively. Model results for the 1999-2002 period show that winter storms are the primary source of water for the lake (Figure $4 a$ ). Water loss by spillover and seepage occurs immediately after these events. Lake water becomes depleted in heavy isotopes after winter precipitation events and becomes progressively heavier with evaporation in subsequent months (Figures $4 b, c, 5$ ). The slopes of modeled lake isotope data roughly match with that recorded in the evaporation pan experiment (Figures 3, 5). By late summer, evaporation reduces the lake to less than a third of its winter size during the period modeled.

The model subcomponents performed well when model variable values were compared with on-site collected data. In isotopic modeling, the average calculated value for the isotopic composition of vapor in the atmosphere, $\delta_{v} \mathrm{D}=-167.4 \%$, agrees well with a measured value of $-161 \%$ for Mauna Kea vapor (Friedman et al. 1964). The Penman equations modeling evaporation rate produced a mean evaporation value of $4.1 \mathrm{~mm} /$ day with a standard deviation of $2.5 \mathrm{~mm} /$ day. This agrees fairly well with the result of the evaporation pan experiment (average $=4.9$ $\mathrm{mm} /$ day) and is in the lower range of values observed by Bean et al. (1994) on Mauna Loa. However, it is likely that the model underestimates actual evaporation slightly. Nullet and Giambelluca (1990, Giambelluca and Nullet 1992) have reported on this deficiency of evaporation models at high altitudes in an analysis of four other distinct methodologies, although Bean et al. (1994) did not find this underestimation in their study of winter evaporation on Mauna Loa. Further research in this area is necessary.

With relatively few data points, the statis-

FIGURE 5. $\delta \mathrm{D}$ versus $\delta^{18} \mathrm{O}$ stable isotope measurements of lake waters and modeled Lake Waiau values. Daily estimated isotopic compositions from a model run with seasonally varying precipitation are indicated by open circles. Inset shows the time sequence of the model isotope points. The lake water becomes enriched in heavy isotopes with a slope similar to that observed during the evaporation pan experiment. 

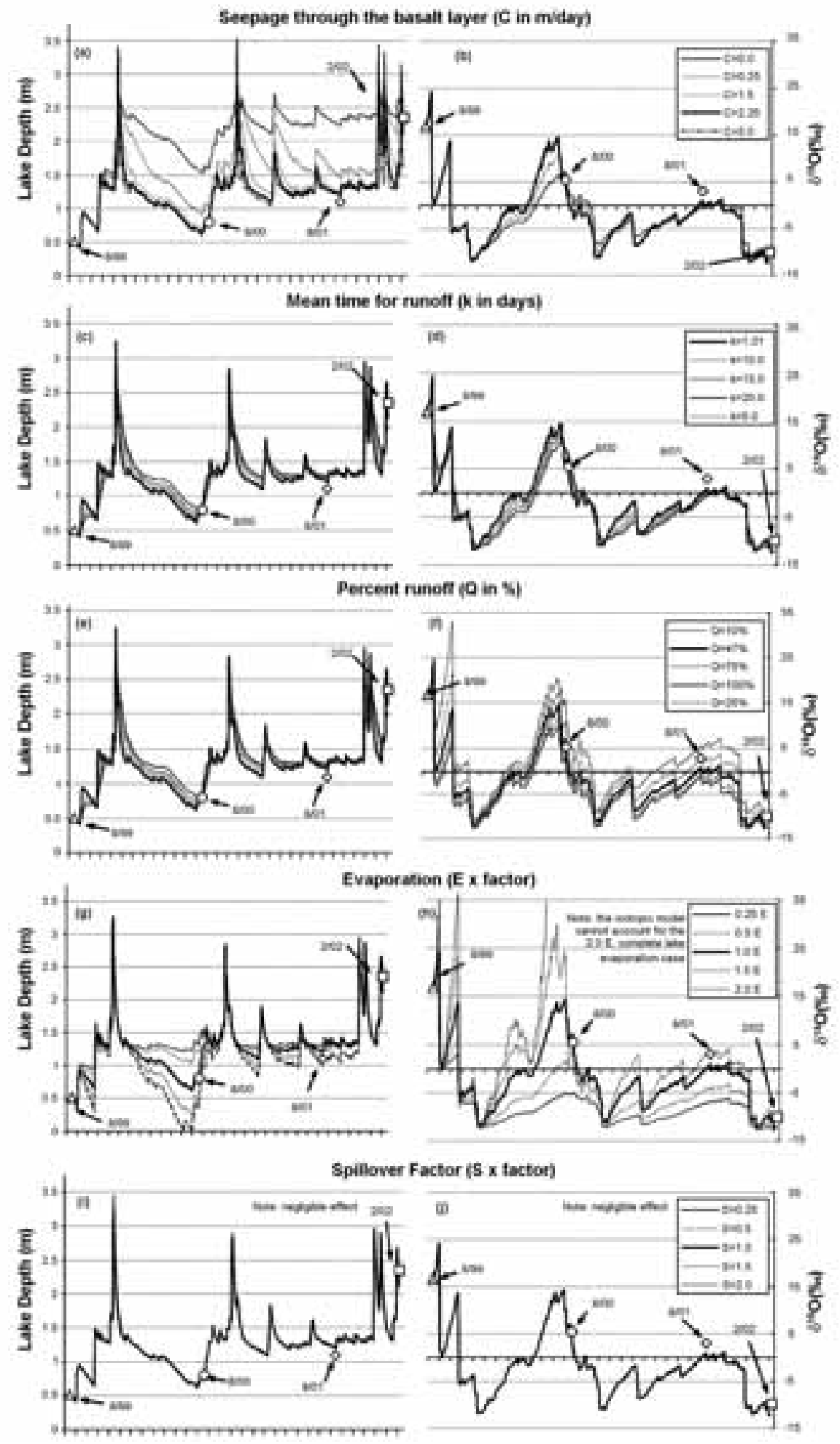
tical significance of model results cannot be established. However, we have conducted sensitivity analyses to examine the relative impacts of each input, output, and unknown parameter on the modeled depth and stable isotope values (Figure 6). Model runs were also made with fixed $\alpha_{\text {evap }}$ factors, fixed as opposed to seasonal isotopic composition of precipitation, and with resultant model values compared with actual values at the beginning instead of the end of each model day. The optimal values for parameters $C, k$, and $q_{f}$ ranged from 0.2 to $2.6 \mathrm{~m} /$ day, 1.0 to 1.4 days, and 15 to $52 \%$, respectively. Although the values of the three parameters varied, model robustness was demonstrated by the fact that the overall depth and isotopic temporal history remained consistently the same (Figure $6)$.

The impact of changes in the magnitude of the spillover function was found to be fairly negligible. The model was found to be most sensitive to evaporation, making the verification of a model of high-altitude evaporation critical to successful application of this modeling technique on high-altitude lakes. The influence of $C$ and $q_{f}$ are also important. It appears that at least a small amount of seepage through the basalt layer is required for the lake to reach the low levels observed in August 2001. In addition, given the large quantities of precipitation that fall in single-day winter storms (Figure 4a), the percentage of water falling into the lake basin that makes it into the lake is critical to determining lake depth and isotopic values, particularly for the first few days after a precipitation event.

Our model predicts sharp spikes in lake level on days with very high rainfall; however, given the basin topography, it is exceedingly unlikely that lake level approaches $3 \mathrm{~m}$ (Figure $4 a$ ). The highest lake levels reported by Woodcock (1980) are $\sim 2.5 \mathrm{~m}$. Several factors likely combine to create these largemagnitude model spikes. First, the runoff and spillover functions are run on too coarse a time scale on days with high precipitation, resulting in a sudden high-volume input pulse rather than gradual filling and spillover over the course of a day. Second, it is possible that the spillover function is calibrated so as to release too little water on days with high rainfall. We have no knowledge of whether the high value of spillover discharge of 164 $\mathrm{m}^{3} /$ day reported by Woodcock (1980) occurred after a large precipitation event. If it did not, the maximum spillover volume per day may be considerably higher. Given the confounding factors above, the optimization program produces a $k$ that is at the lowermost value of the constrained range. Because the lake has never been recorded at depths greater than $2.5 \mathrm{~m}$ and given the extent of its drainage basin, we suspect that a higher $k$, which corresponds to slower input and lower-magnitude "spikes," is the physical reality that would result in a more muted hydrograph.

\section{DISCUSSION}

Examination of isotopic data and preliminary modeling show that winter precipitation, which is isotopically light, is the main source of water for both Lake Waiau and downslope springs. On the other hand, the lake was found to have extraordinarily high $\delta \mathrm{D}$ and $\delta^{18} \mathrm{O}$ values in the summer due to the effects of extensive evaporation. Finally, we conclude that precipitation alone, collected in the $\mathrm{Pu}^{6} \mathrm{u}$ Waiau cinder cone surface catchment area, is sufficient to fill and sustain the lake.

The constructed hydrologic model of Lake Waiau is preliminary insofar as further validation and calibration are necessary to assess day-to-day modeling precision. An intensive sampling period of at least a week in which

FiguRE 6. Lake Waiau depth and ${ }^{18} \mathrm{O}$ model sensitivity to select parameters. Except as indicated in figure legends, sensitivity analysis model runs were made with the optimized values of the three parameters $(C=2.25 \mathrm{~m} /$ day; $k=1.01$ days; and $q_{f}=47 \%$ ). Sensitivity to all inflows and outflows is assessed. $a$ and $b$, Seepage of the basalt flow for $C=0.0-$ $5.0 \mathrm{~m} /$ day. $c$ and $d$, Mean time for runoff for $k=1.01-20.0$ days. $e$ and $f$, Percentage of runoff reaching the lake for $Q=10-100 \% . g$ and $h$, Modeled evaporation multiplied by a factor of $0.25-2.0 . i$ and $j$, Modeled spillover multiplied by a factor of $0.25-2.0$. 
measurements are obtained both before and after a large rainstorm is needed to fully calibrate model input and output functions. However, the data and model successfully and consistently present a story of a lake that fills with isotopically light water during winter storms and is then driven to low levels and extremely heavy isotope ratios by extensive evaporation.

Our analyses also suggest outstanding questions that further research must address to refine understanding of the hydrology of Lake Waiau. A high priority in future work must be collection of subsurface data in and around the lake basin to understand the presence and nature of the impermeable layer underlying the lake basin and the precise degree to which it is impermeable. The results from our volumetric and isotopic model of Lake Waiau produce a picture that is consistent with no groundwater input; however, the possibility cannot be excluded without further research. This information is critical to making summit land-use decisions that affect the lake. To better understand changes in the lake over long periods of time, a program of depth measurements and isotopic sampling of Lake Waiau spaced at regular intervals throughout the year should be undertaken. If coupled with installation of a weather station near the lake, this could be used to further refine the predictive hydrologic model and assess response of the lake to changing climatic conditions. As we improve understanding of the geology, meteorology, and hydrology of Lake Waiau and the surrounding summit region, we collect information needed to better protect this sacred landmark.

\section{ACKNOWLEDGMENTS}

We thank Betsy Gagné and William Stormont for assistance with access to the Mauna Kea Ice Age Natural Area Reserve (site of Lake Waiau), R. Koehler for assisting with sample collection, and D. Medcalf for supplying VLBA meteorological data. F. Seelos provided valuable model programming assistance, and R. Morris and S. Rovito gave helpful reviews of the manuscript. We also thank two anonymous reviewers for their insightful comments.

\section{Literature Cited}

Bean, C., J. O. Juvik, and D. Nullet. 1994. Mountain evaporation profiles on the island of Hawaii. J. Hydrol. (Amst.) 156:181-192.

Box, M. 1965. A new method of constrained optimization and a comparison with other methods, Comput. J. 8:42-52.

Bras, R. 1990. Hydrology: An introduction to hydrologic science. Addison Wesley, Reading, Massachusetts.

Chow, V. T., ed. 1964. Handbook of applied hydrology. McGraw-Hill Book Company, New York.

Coleman, M. L., T. J. Shepherd, J. J. Durham, J. E. Rouse, and G. R. Moore. 1982. Reduction of water with zinc for hydrogen isotope analysis. Anal. Chem. 54 (6): $993-$ 995.

Craig, H. 1961. Isotopic variations in meteoric waters. Science (Washington, D.C.) 133:1702-1703.

Criss, R. 1999. Principles of stable isotope distribution. Oxford University Press, New York.

Friedman, I., A. Redfield, B. Schoen, and J. Harris. 1964. The variation of the deuterium content of natural water in the hydrologic cycle. Rev. Geophys. 2:177-224.

Garbrecht, J., and L. W. Martz. 1995. TOPAZ: An automated digital landscape analysis tool for topographic evaluation, drainage identification, watershed segmentation and subcatchment parameterization; overview. NAWQL 95-1, U.S. Department of Agriculture, Agricultural Research Service, National Agricultural Water Quality Laboratory, Durant, Oklahoma.

— 1997 . The assignment of drainage direction over flat surfaces in raster digital elevation models. J. Hydrol. (Amst.) 193:204-213.

Giambelluca, T. W., and D. Nullet. 1992. Evaporation at high elevation in Hawaii. J. Hydrol. (Amst.) 136:219-235.

Gregory, H. E., and C. K. Wentworth. 1937. General features and glacial geology of Mauna Kea, Hawaii. Geol. Soc. Am. Bull. 58:1719-1742.

Group 70 International, Inc. 2000. Mauna 
Kea Science Reserve master plan. June. Prepared for The University of Hawai' $i$, Honolulu (available at http://www.hawaii. edu/maunakea/).

Kinzie III, R., A. Banaszak, and M. Lesser. 1998. Effects of ultraviolet radiation on primary productivity in a high altitude tropical lake. Hydrobiologia 385:23-32.

Massey, J. 1978. Lake Waiau: A study of a tropical alpine lake, past and present. Ph.D. diss., University of Hawai'i at Mānoa, Hawai'i.

Nullet, D., and T. W. Giambelluca. 1990. Winter evaporation on a mountain slope, Hawaii. J. Hydrol. (Amst.) 112:257-265.

Ponce, M. 1989. Engineering hydrology. Prentice-Hall, Englewood Cliffs, New Jersey.

Reichhardt, T. 2002. NASA faces legal challenge over Hawaiian telescope plan. Nature (Lond.) 417:5.

Scholl, M., S. Ingebritsen, C. Janik, and J. Kauahikaua. 1996. Use of precipitation and groundwater isotopes to interpret regional hydrology on a tropical volcanic island: Kilauea volcano area, Hawaii. Water Resour. Res. 32:3525-3537.

Schroeder, T. 1993. Climate controls. Pages 12-55 in M. Sanderson, ed. Prevailing trade winds climate and weather in Hawaii. University of Hawai'i Press, Honolulu.
Singh, V. 1992. Elementary hydrology. Prentice-Hall, Englewood Cliffs, New Jersey.

Stearns, H. T., and G. A. Macdonald. 1946. Geology and ground-water resources of the island of Hawaii. Bull. 9. U.S. Geological Survey, Honolulu.

Ugolini, T. 1974. Hydrothermal origin of the clays from the upper slopes of Mauna Kea, Hawaii. Clays Clay Miner. 22:189194.

U.S. Geological Survey. 1982. Digital Elevation Model (DEM) from Mauna Kea, HI and Ahumoa, HI quadrangles, 7.5 minute series (topographic). U.S. Government Printing Office, Washington, D.C.

Woodcock, A. 1980. Hawaiian alpine lake level, rainfall trends, and spring flow. Pac. Sci. 34:195-209.

Woodcock, A. H., and W. Groves. 1969. Negative thermal gradient under alpine lake in Hawaii. Deep-Sea Res. 16:393405.

Woodcock, A. H., M. Rubin, and R. A. Duce. 1966. Deep layer of sediments in alpine lake in the tropical mid-Pacific. Science (Washington, D.C.) 154:647-648.

Zohdy, A., and D. B. Jackson. 1969. Application of deep electrical soundings for groundwater exploration in Hawaii. Geophysics 34:584-600. 